\title{
The Impact of Quality Management Purchasing Practices on Purchasing Performance in Transitional Economies
}

\author{
Bojan LALIĆ, Milan DELIĆ, Nenad SIMEUNOVIĆ, Nemanja TASIĆ, Sreten CVETKOVIĆ
}

\begin{abstract}
This study examines the nature of relationships between quality management practices in purchasing and purchasing-related organisational performance within ISO 9001:2008 environment in transitional economies. The study was based on managers' responses from 90 ISO 9001:2008 certified large organisations from Serbia. The findings show that quality management practices in purchasing positively affect purchasing performance. Further, purchasing performance is found to be a significant mediator between quality management practices and time-based performance. However, despite the overall good predictive model power, the explained variance on timebased performance is quite low. Thus, the effects on time-based performance are arguable. PLS-SEM Importance-performance analysis reveals that purchasing performance, cross-functional coordination and personnel management have relatively high performance, while benchmarking has the lowest value of the performance index. Consequently, the implementation of quality management practices in purchasing along with ISO 9001:2008 might be a part of a good strategic choice for transitional organisations to overcome troublesome transitional times. Still, the discrepancies between this study and the results from developed economies yield potential improvement areas on how organisations in transitional economies should manage purchasing practices.
\end{abstract}

Keywords: quality management; purchasing performance; PLS-SEM; transitional economy

\section{INTRODUCTION}

The increasing trends in outsourcing rates of companies' expenditure have affected the very nature of the purchasing function [41]. It has outgrown its purely operational role. Paulraj et al. highlight that purchasing has evolved from a set of "buying" activities to "procurement" and "supply management" [27].

Although purchasing has been recognised as supply chains driving force, implementing such a practice is still an issue [27]. The alignment of purchasing and organisational strategies, reaching functional and other organisational objectives in purchasing, and managing the purchasing function as an integral part of an organisation are only a few of many challenges being still a subject of debate [27, 41]. Some academics have underlined the synergetic nature of strategic purchasing - quality management relation, emphasizing that purchasing should be based and managed on quality management principles [15]. Related studies, like [32] and [15], have provided extensive review of this subject. To the best of our knowledge, they have provided the most comprehensive research model of quality management practices in purchasing so far.

This paper aims to extend the studies of [32] and [15]. To test the convenience of managing the purchasing function based on quality management principles, the model of quality management practices in purchasing is assessed within the ISO 9001:2008 environment. Managers' responses from 90 ISO certified organisations were used to test the research model. The model was empirically tested in Serbian transitional economy. In contrast to the period after WWII, where Serbian economy was planned and imposed by the governing party, today's open markets in Serbia are "left alone". In the absence of governing superior authority and centrally imposed bureaucratic control, organisations have to develop their own strategies. This study provides insights into how quality management practices within ISO 9001:2008 environment can serve as a basis for developing purchasing strategies and how organising the purchasing function based on quality management principles might help organisations to adapt, survive and achieve growth in transitional conditions.

The importance-performance matrix analysis (IMPA) was carried out to provide guidelines for both managers and scholars, in identifying determinants with low performance. Usually, these are the major areas of potential improvements.

\section{LITEATURE REVIEW}

There is a firm belief among scholars and practitioners that supply management is a source of competitive advantage, e.g. [21, 24, 47]. For instance, [21] claim that the strategic role of the supply chain management is a "fact of life". However, many organisations have only recently become aware of this. In the past, supply management was seen as a "clerical" system primarily responsible for placing buys, managing orders and information flows with suppliers [29]. Today, the supply management concept has stretched to the point where managers are dealing with customer service, supply continuity, risk management, environmental performance, and higher product and service quality $[21,45]$. Thus, over time, the importance of effective and efficient supply management becomes widely recognised and the strategic role of purchasing emerged along. The role of purchasing was always implied in discussions about supply management. Recently published papers, e.g. [12], clearly differ from earlier studies, which treat purchasing as a secondary and supportive activity. Thus, a relatively new paradigm called "concurrent purchasing" is used to describe purchasing as a strategic process, rather than a separate function in an organisation [3].

A consensus about the strategic potential of purchasing is somehow reached [30], but some issues still raise concerns among scholars and practitioners. Traditional (e.g. supply management) or emerging (e.g. green management, corporate social responsibility, innovation, risk management, human resource management, disaster management), such issues are directly or indirectly related to the purchasing function development stages, ranging from clerical to integrative $[29,30,24,11]$. On the clerical level, the purchasing function is seen as a decision process of lesser 
importance, a less integrative and purely operational set of activities. However, the purchasing function can take a proactive role with a long-term focus. Besides crossfunctional communication and coordination (internal), the purchasing function is oriented towards the strategic development and continual involvement of suppliers (external). Essentially, on the clerical level, the purchasing function is considered to be "immature" [11], focused mostly on the quality control of suppliers' products/services, placed orders and corrective actions. On the strategic level, purchasing is considered to be "mature" [11] and more about taking preventive actions to mitigate certain risks and overcome potential shortfalls.

Thus, most of the major purchasing issues are quality management-related problems. Often, these are the major improvement areas of quality management excellence models (e.g. EFQM, ISO 9004). In other words, it seems that purchasing issues and quality management are firmly related at various stages of the purchasing function development phases. For example, it is known that purchased materials produce variation in product quality, e.g. [7]. In addition, quality-related purchasing decisions have a potentially strong impact on the end product/service and organisational performance [15]. However, only a few scholars have investigated the adoption of quality management concepts in purchasing, e.g. [3, 13, 42]. For example, [3] highlight the need for purchasing strategies and a high degree of purchasing involvement within TQM. González-Benito et al. found TQM and ISO 9000 to be important features in the customer-supplier relationship [13]. While ISO 9000 is a prerequisite for competing in global markets, the advantages of TQM in purchasing are shown through benchmarking activities, identifying improvements, quality management tools and improving team work. Rodríguez and Lorente highlight that companies no longer rely solely on detection activities to assure the products quality, but rather focus on preventing quality defects [42]. Therefore, an organisation needs to engage both internal (employees) and external (suppliers) resources to achieve product and service quality improvements. Thus, commitment to TQM implies that the purchased materials are equally important as the quality of products and services delivered to customers. This is where the role of the purchasing function steps to the forefront [42].

The role of the purchasing function becomes even more important for organisations in transitional economies. The shift from highly planned and regulated markets (i.e. five-year development plans), centralised and imposed by the governing party, to more open and free markets for all participants (liberalisation), imposes the need for organisations to develop adequate purchasing strategies. In the socialist economy, the government allocated goods and services and the purchasing function had a mostly "clerical" role in managing direct bargaining between buyers and sellers [38]. Essentially, transitional organisations are "left alone" to figure out that supplier selection and assessment might be important, applied along with other "new" practices.

Such practices include a wide range of operational and strategic activities like buyer-supplier relationship development, supply base leveraging and supplier performance evaluation $[27,46]$. With the growing need to establish long-term relationships with suppliers, certain issues regarding the adoption of quality management into these practices have been raised [32, 15]. For instance, [32] and [15] have conducted an extensive review of quality management literature and identified 22 quality management-related purchasing practices. These are: supplier quality management (SQM), personnel management (PM), cross-functional coordination (CCO), management commitment (MC) and benchmarking (BM). Naturally, other dimensions can be used for research purposes, but it could be argued that these dimensions capture the "essence" of quality management in purchasing. Thus, they were adopted to constitute a research model in this study.

\section{THE RESEARCH MODEL \\ 3.1 Dimensions of Quality Management Practices in Purchasing}

\section{Supplier quality management (SQM)}

Kaynak and Hartley and Hemsworth et al. emphasise the importance of the early involvement of suppliers (even) in the design of new products and/or services through: occasional trainings, certification of suppliers' quality management systems, visits paid to the suppliers and the existence of particular extra rewards/compensations for the suppliers' good quality $[17,15]$. Also, rather than having a wide range of suppliers, effective supplier quality management is achievable with fewer suppliers that are capable to deliver desirable quality and quantity in a long term. Such actions could foster supplier commitment to product design and quality [16].

\section{Personnel management (PM)}

Personnel management construct measures the level of autonomy in decision making and the extent of employee involvement in problem solving activities [15]. Supplier selection and ranking are activities not to be carried out without employee active participation [15]. Thus, many authors emphasize the importance of employee trainings, e.g. [16], employee results recognition and the development of effective problem solving skills [17].

Cross-functional coordination (CCO)

The complexity of the production/service provision implies effective cooperation between functions, teamwork and diverse knowledge in solving complex problems [15]. Thus, cross-functional employee coordination in the product/service development and active participation of purchase staff in other organisational activities are an inherent part of purchasing practices [17].

Management commitment (MC)

Many studies claim that management commitment plays a key role in every aspect of quality management. According to [15], two elements are important for determining the level of commitment. These are whether management emphasises the importance of quality for the purchased product and whether the performance of purchase management is determined upon the quality of the purchased goods. Additionally, managers' commitment and encouragement of employees to take part in system changes is found to be quite important [17].

\section{Benchmarking (BM)}

Hemsworth et al. emphasise the importance of benchmarking in the quality and price of the purchased goods, purchasing process as a whole and purchasing performance [15]. In addition, benchmarking activities are often followed by an extensive use of information technologies and software support within an information system. 


\subsection{Purchasing-Related Organisational Performance (Outputs)}

This study also incorporates the measures of purchasing performance and time-based performance (i.e. purchasing-related organisational performance). Consequently, if any are existent, the positive effects of quality management practices should be manifested via the enhancement of purchasing performance. Also, such effects should result in the reduction of production/service lead times and time-to-market.

\section{Purchasing performance (PPF)}

Purchasing performance measures are adopted from [15]. They are the measures of the differences between actual and target prices for a product and services, the level to which they comply with the given specifications, as well as the ability to achieve the on-time delivery.

\section{Time-based performance (TPF)}

Time-based performance measures are adopted from [40]. These are: production/service cycle time, defect and rework rate/service repeated due to poor quality, production/service reliability, inventory turnover rate and time-to-market.

\subsection{Quality Management Purchasing Practices within ISO 9001:2008 Environment}

The implementation of quality management practices is determined by the maturity of quality culture [37] Quality culture formulation occurs through integrated quality-oriented organisational changes [37]. Besides TQM and other quality management improvement programs, using ISO 9000 standard series and other related management standards is recognised as a sign of quality culture, [37, 20]. For example, ISO 9001:2008 provides this through the conformance with various standard clauses (Tab. 1).

Table 1 Relationship between quality management practices in purchasing and ISO 9001:2008 clauses

\begin{tabular}{|l|l|}
\hline \multicolumn{1}{|c|}{$\begin{array}{c}\text { Quality management purchasing } \\
\text { practices }\end{array}$} & \multicolumn{1}{c|}{$\begin{array}{c}\text { Reference to ISO 9001:2008 } \\
\text { clauses }\end{array}$} \\
\hline \multirow{2}{*}{ Supplier quality management } & $\begin{array}{c}4.1 \text { - Process outsourcing } \\
7.4 \text { - Purchasing }\end{array}$ \\
\hline Personnel management & 6.2 - Human resources \\
\hline \multirow{2}{*}{ Cross-functional coordination } & $\begin{array}{l}5.5 .3 \text { - Internal communication } \\
6.3 \text { - Infrastructure }\end{array}$ \\
\hline \multirow{2}{*}{ Management commitment } & 5.1 - Management commitment \\
& 5.5 .2 - Management representative \\
\hline Benchmarking & 8.4 - Analysis of data \\
\hline
\end{tabular}

Also, the use of quality management standards is recognised by many organisations in emerging and developing economies as a mechanism for organisational growth and a prerequisite for global business [40, 5]. Some findings show a booming number of ISO compliant certifications in "post-Soviet" economies like China, Hungary, Czech Republic and Poland, e.g. [35, 31]. Such healthy growth in numbers is followed by an extensive research work about the effects of ISO management systems. While some authors report positive results, e.g. $[37,20]$, other findings are unfavourable at best, e.g. [40, 33]. Thus, it is worth mentioning that desirable effects and higher quality are not always achievable with ISO standards, and it is obvious that ISO 9000 does not necessarily produce positive effects on organisational performance. Still, it could be argued that quality management practices can be fostered within ISO 9001:2008 environment. At least, ISO 9001:2008 can provide a good basis for continual improvement and performance development programs.

\subsection{Relationship between Research Dimensions}

Many practitioners and scholars underline that quality culture empowerment and quality management practices implementation are highly affected by the extent to which top management is committed to quality, i.e. $[10,17]$. Thus, top management affects almost every crucial aspect of quality improvement programs. Active involvement of employees and cross-functional coordination in solving quality-related issues are most influential. Without top management support and clear guidance, employees might fail to recognise the importance of quality improvement programs. For example, Yamada et al. underline the lack of leadership support and communication between employees to be top reasons for failure of quality management practices [39]. Similarly, management could also affect the transferability of benchmarking outputs, organisational knowledge, and experience, especially if such information conflicts organisational culture, management structures and leadership styles [23]. Thus, the following assumptions are set:

H1: Management commitment is positively related to personnel management;

H2: Management commitment is positively related to cross-functional coordination; and

H3: Management commitment is positively related to benchmarking.

Mentzer et al. highlight that purchasing, logistics, production management, and marketing are separate organisational functions, but highly dependent on one another [22]. Thus, to achieve effective supply chain management, integration of these functions is necessary. Recently published data show that cross-functional coordination enables synergy potentials from purchasing and supply management operations to be realised in the form of economies of scale, scope, process and learning [11]. To enhance organisational flexibility, crossfunctional teams must be established to support process integration in the supply chain and purchasing [4]. Chin et al. suggest that cross-functional approach fosters human skills and employee empowerment [4]. Such practices are shown to be more beneficial for supplier relationships and improved operational performance [6]. This implies the following assumptions:

H4: Cross-functional coordination is positively related to personnel management; and

H5: Personnel management is positively related to supplier quality management.

Benchmarking is found to be an essential practice in supply chains [34] and quality management [1]. Benchmarking can help purchasing managers to identify suppliers that could benefit most from supplier development efforts. Therefore, evaluation and improvement of purchasing processes through benchmarking of best industry practices potentially brings the most beneficial suppliers for an organisation [15]. 
Benchmarking the supply chain performance against the best practice in industry can encourage further improvements in increased sales [19]. Thus, it could be assumed that:

H6: Benchmarking is positively related to supplier quality management.

Since the quality of the purchased products/services affects the production process [43] and the final product quality [10], suppliers' promptness and flexibility should follow organisations' cycle times $[1,16]$. Therefore, relationships with suppliers should positively affect purchasing performance and time-based performance as well. This implies that:

H7: Supplier quality management is positively related to time-based performance;

H8: Supplier quality management is positively related to purchasing performance; and

H9: Purchasing performance is positively related to time-based performance.

The hypothesized model is given in Fig. 1.

\section{RESEARCH METHOD}

\subsection{Measures and Questionnaire Development}

The questionnaire was developed in accordance with [36]. Thus, only measures with a theoretical backbone and empirical validation were included, e.g. [44, 15, 40]. Before a pilot test, a group of university professors checked face validity. According to their recommendations, minor corrections were made. The pilot test was conducted with fifteen companies from various industries. Purchasing managers from each of these companies were asked to assess the questionnaire. Generally, there were not any major complaints about the length or clarity of the research instrument. Finally, the research instrument contained 28 items grouped into five dimensions of quality management practices in purchasing, and one dimension for each of the purchasing performance and time-based performance. For acquiring respondents' subjective estimates, a seven-point Likert scale was used [25].

\subsection{Data Collection and Sample}

An initial list of large Serbian organisations was made according to data provided by [26]. There are 494 organisations in Serbia classified as "large" (with more than 250 employees). Further, a representative sample size of 96 organisations $(\alpha=0,05, t=1,96)$ for this population was calculated [2]. However, due to a potential low response rate, 250 organisations were randomly selected to constitute the research sample. Each organisation was contacted and an invitation letter was sent to their purchasing managers. As a minimum, conformance with the ISO 9000 standard was a prerequisite for an organisation to be included into the survey. Out of 250, 159 respondents expressed a desire to take part.

An electronic version of the questionnaire was distributed to purchasing managers. To minimise the bias effect, only one reply per email address (i.e. organisation) was accepted. Further activities were conducted following the [9] approach. The administration process was followed by a series of follow-up email reminders if needed. After a three-month period, out of 159,90 responses were valid.

\subsection{Sample Demographics}

Out of 90 respondents (purchasing managers), 58 $(64,4 \%)$ were males and $32(35,6 \%)$ females. Further, 7 $(7,8 \%)$ respondents were below the age of $30,22(24,4 \%)$ of them were between the age of 31 and 40, $33(36,7 \%)$ respondents fell into the age category between 41 and 50 , while $28(31,1 \%)$ respondents were older than 51 . Production $(33 ; 36,7 \%)$, service $(30 ; 33,3 \%)$ and production/service $(27 ; 30 \%)$ types of organisations were nearly equally presented in the sample. Tab. 2 shows sample demographics by industry sectors.

Table 2 Sample demographics by industry sectors
\begin{tabular}{|l|c|c|}
\hline Sector & $N$ & $\%$ \\
\hline Industrials & 54 & 48,65 \\
\hline Agriculture & 5 & 4,5 \\
\hline Mining and energetics & 1 & 0,9 \\
\hline Traffic & 4 & 3,6 \\
\hline Public utilities & 2 & 1,8 \\
\hline Trade & 11 & 9,91 \\
\hline Chemical and pharmaceutical & 5 & 4,5 \\
\hline Education and culture & 2 & 1,8 \\
\hline Telecommunications & 1 & 0,9 \\
\hline Information technology & 7 & 6,31 \\
\hline Health care & 5 & 4,5 \\
\hline Other & 14 & 12,61 \\
\hline & 111 & 100,00 \\
\hline
\end{tabular}

Note: Some organisations fall into several categories.

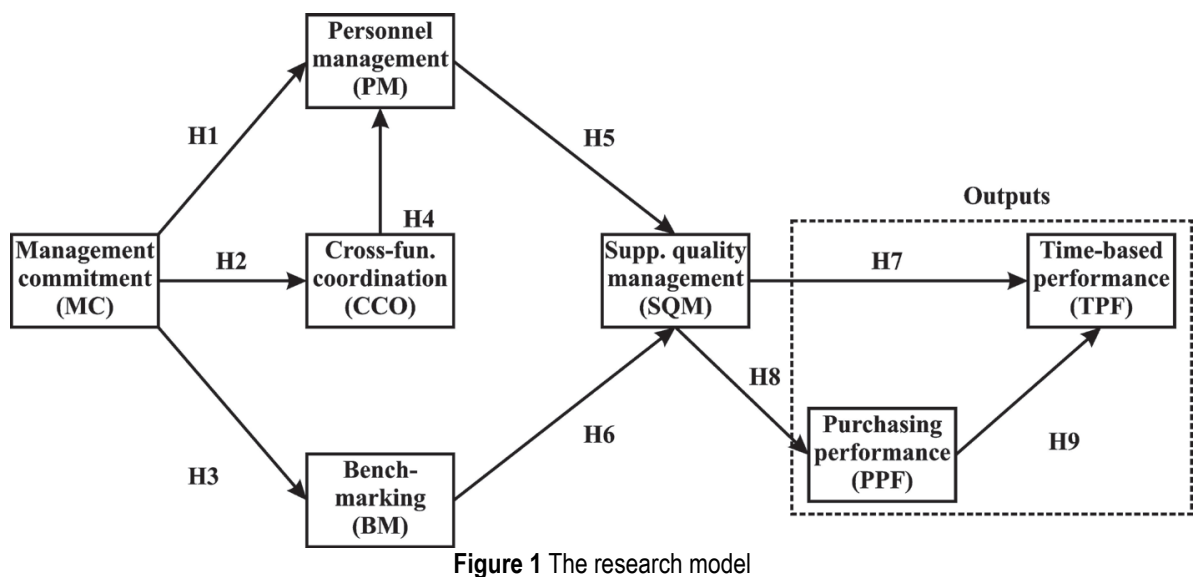




\section{DATA ANALYSIS}

This study was based on PLS-SEM method for two main reasons. The first one is the sample size. PLS-SEM works efficiently with small sample sizes and makes practically no assumptions about the underlying data [14] Also, applying PLS-SEM with a relatively small sample size results in higher efficiency of parameter estimation and greater statistical power [14]. The second one is the exploratory nature of this study [14]. Although previously used, e.g. $[44,15]$, these constructs were not tested in the context of Serbian transitional economy.

The research model was evaluated using a two-step approach [14]. First, the measurement model was assessed. Research hypotheses and structural model evaluation were carried out afterwards.

\subsection{Measurement Model}

A reflective measurement model was used. Hence, internal consistency (composite reliability), convergent and discriminant validity were conducted [14]. First, an internal consistency test was carried out (Cronbah's $\alpha,[25$, 14]). Accordingly, composite reliability values of 0,70 and above are acceptable in exploratory research [25]. Further, outer loadings and average variance extracted (AVE) were used to check convergent validity [14]. Outer loadings for only two indicators of time-based performance were below the recommended value (at least 0,7 ); thus they were removed. Outer loadings for other indicators were statistically significant and AVE value was at least at 0,5 for each construct [14]. Finally, Fornell-Larcker criterion for discriminant validity showed good results [14]. These are shown in Tab. 3 .

Table 3 Measurement model reliability and validity tests

\begin{tabular}{|c|c|c|c|c|c|c|c|c|c|c|}
\hline 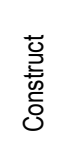 & 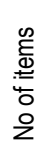 & 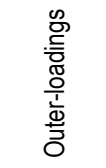 & $\alpha$ & 1 & 2 & 3 & 4 & 5 & 6 & 7 \\
\hline SQM & 4 & $0,72-0,75$ & 0,72 & $0,73^{*}$ & & & & & & \\
\hline PM & 4 & $0,76-0,86$ & 0,82 & 0,63 & $0,80^{*}$ & & & & & \\
\hline $\mathrm{CCO}$ & 4 & $0,77-0,81$ & 0,81 & 0,53 & 0,77 & $0,80^{*}$ & & & & \\
\hline $\mathrm{MC}$ & 4 & $0,76-0,84$ & 0,82 & 0,59 & 0,77 & 0,75 & $0,80^{*}$ & & & \\
\hline BM & 4 & $0,72-0,87$ & 0,82 & 0,54 & 0,53 & 0,55 & 0,64 & $0,81^{*}$ & & \\
\hline PPF & 4 & $0,69-0,83$ & 0,79 & 0,49 & 0,55 & 0,50 & 0,57 & 0,40 & $0,78^{*}$ & \\
\hline TPF & $2^{\star \star}$ & $0,86-0,95$ & 0,79 & 0,14 & 0,30 & 0,44 & 0,34 & 0,31 & 0,26 & $0,90^{*}$ \\
\hline
\end{tabular}

\subsection{Structural Model}

The structural model was tested against several criteria [14]. First, collinearity analysis was carried out using VIF (variance inflation factor). Since all of the VIFs were below the value of 3,3 , collinearity was not an issue. Second, a boots trapping technique with 5000 sub-samples reveals that only the relationship between supplier quality management practices and time-based performance was not statistically significant. Finally, coefficients of determination ( $R^{2}$ values) were found to be mostly moderate, ranging from 0,242 for purchasing performance to 0,680 for personnel management. However, the $R^{2}$ value for time-based performance was found to be low $(0,067)$.
Thus, the predictive power of the model regarding the effects on this construct is arguable. Path coefficients are shown in Tab. 4.

\begin{tabular}{|c|c|c|c|c|c|c|}
\hline Hypothesis & Path & $\begin{array}{l}\text { Original } \\
\text { sample }\end{array}$ & $\begin{array}{c}\text { Sample } \\
\text { mean }\end{array}$ & $\begin{array}{c}\text { Stand. } \\
\text { dev. }\end{array}$ & $T$ & $P$ \\
\hline $\mathrm{H} 1$ & $\mathrm{MC} \rightarrow \mathrm{PM}$ & 0,453 & 0,460 & 0,098 & 4,613 & 0,000 \\
\hline $\mathrm{H} 2$ & $\mathrm{MC} \rightarrow \mathrm{CCO}$ & 0,749 & 0,753 & 0,049 & 15,225 & 0,000 \\
\hline H3 & $\mathrm{MC} \rightarrow \mathrm{BM}$ & 0,643 & 0,648 & 0,062 & 10,337 & 0,000 \\
\hline $\mathrm{H} 4$ & $\mathrm{CCO} \rightarrow \mathrm{PM}$ & 0,429 & 0,424 & 0,104 & 4,121 & 0,000 \\
\hline $\mathrm{H} 5$ & $\mathrm{PM} \rightarrow \mathrm{SQM}$ & 0,480 & 0,482 & 0,104 & 4,620 & 0,000 \\
\hline $\mathrm{H} 6$ & $\mathrm{BM} \rightarrow \mathrm{SQM}$ & 0,288 & 0,294 & 0,105 & 2,755 & 0,006 \\
\hline H7 & $\mathrm{SQM} \rightarrow \mathrm{TPF}$ & 0,017 & 0,025 & 0,134 & 0,128 & $0,898^{*}$ \\
\hline $\mathrm{H} 8$ & $\mathrm{SQM} \rightarrow \mathrm{PPF}$ & 0,492 & 0,504 & 0,083 & 5,951 & 0,000 \\
\hline $\mathrm{H} 9$ & $\mathrm{PPF} \rightarrow \mathrm{TPF}$ & 0,250 & 0,258 & 0,120 & 2,075 & $0,038^{* \star}$ \\
\hline
\end{tabular}

\section{RESULTS AND DISCUSSION}

The results show that "purchasing performance" construct has the highest value for performance index $(71,98)$, followed by cross-functional coordination $(64,416)$ and personnel management $(64,15)$. Further, management commitment $(60,614)$ and supplier quality management $(59,151)$ have considerable performance values. With the lowest value for performance, benchmarking is the weakest determinant $(45,278)$. The importance-performance output for the time-based performance should be taken with a grain of salt, due to the low $R^{2}$ value $(0,067)$. The results of the importanceperformance analysis are given in Tab. 5 .

\begin{tabular}{|c|c|c|c|c|c|c|c|c|}
\hline LV & BM & $\mathrm{CCO}$ & PM & SQM & PPF & TPF & 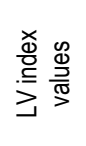 & 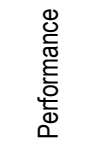 \\
\hline $\mathrm{MC}$ & 0,641 & 0,761 & 0,742 & 0,514 & 0,201 & 0,058 & 4,637 & 60,614 \\
\hline $\mathrm{CCO}$ & - & - & 0,404 & 0,187 & 0,073 & 0,021 & 4,865 & 64,416 \\
\hline PM & - & - & - & 0,462 & 0,181 & 0,052 & 4,849 & 64,150 \\
\hline BM & - & - & - & 0,267 & 0,104 & 0,030 & 3,717 & 45,278 \\
\hline SQM & - & - & - & - & 0,390 & 0,113 & 4,549 & 59,151 \\
\hline PPF & - & - & - & - & - & 0,253 & 5,429 & 71,975 \\
\hline TPF $^{*}$ & - & - & - & - & - & - & $4,711^{*}$ & $54,223^{*}$ \\
\hline
\end{tabular}

Thus, the importance-performance matrix (IMPA) data reveal similarities, as well as discrepancies between this study and the results from developed economies. Consequently, previous studies from developed economies also show a strong influence of purchasing performance, cross-functional coordination and personnel management, e.g. $[32,15]$. These results are in accordance with relevant literature findings. However, the moderate performance of management commitment and supplier quality management in transitional economy should not be taken lightly. In order to develop supply chains, a more active enrolment and involvement of purchasing managers with employees in quality improvement programs might be an appropriate course of future actions. Previous studies from the research population provide further evidence on this subject [28, 8]. Radlovački et al. reveal a lack of awareness of organisations' management about the importance of applying management principles [28]. Similarly, Delić et 
al. point to the shortcomings of top managers' work, passivity of senior management in the improvement programs and the absence of leadership [8]. Bearing this in mind, it is worth mentioning that passivity and inappropriate expectations of quality managers might produce the shortcomings of ISO 9000 [40], which eventually might lead to undesirable effects in purchasing practices.

Further, the development of purchasing management in transitional economy is doubtful without strategies for long-term relations among supply chain members. To develop supply chains in a real sense, integration between buyers and suppliers under the holistic quality management concepts is a prerequisite. Currently, supply chain management in Serbia is characterised by numerous deficiencies, including limited abilities in building valuable forward relations, weak strategic planning, infrastructural problems and other major obstacles for fast development of supply chains [18]. Hence, actions of future improvements should exceed the context of ISO 9001:2008 and should be oriented towards the implementation of quality management excellence models (e.g. ISO 9004, TQM). Simply put, it seems that the application of ISO 9001:2008 in the case of Serbian organisations is a necessary, but not sufficient factor for overall successful business.

The lowest performance of benchmarking brings the biggest concern regarding how managers organise their purchasing activities and conduct business. Such results show significant discrepancy with relevant scholarly opinions. Benchmarking key role is well known and has become a common practice in developed economies [34]. High performing organisations have used benchmarking as a way to identify and understand what practices are necessary to reach world-class standards [34]. Thus, without proper consideration of benchmarking tools, the development of purchasing practices towards strong supply chain relations in transitional markets is arguable.

Finally, due to the low $R^{2}$ value $(0,067)$, it is difficult to argue that supplier quality management along with the purchasing performance in the case of Serbian transitional economy produces positive results on time-based performance. So, future research towards further clarification of this issue is needed.

\section{CONCLUSION}

This study contributes to the field of quality management by examining the relationships between quality management purchasing practices within ISO 9001:2008 environment, in the conditions of transitional economy. This study of 90 ISO 9001:2008 certified Serbian organisations reveals similarities with, as well as discrepancies between state of the art literature findings and study results from developed economies. Similarities are shown through the relatively high performance of purchasing performance, personnel management and cross-functional coordination. Moderate IMPA values for management commitment and supplier quality management, as well as low benchmarking performance call for careful interpretation of the study results. Further, it is difficult to argue that supplier quality management along with purchasing performance produces positive results on time-based performance. Overall, it seems that the implementation of quality management practices in purchasing within ISO 9001:2008 environment is a relatively good strategic choice for Serbian organisations to overcome troublesome times. However, further improvements of quality management practices are needed. Most likely such actions should be oriented towards the implementation of quality management excellence models in purchasing practices.

\section{REFERENCES}

[1] Ahire, S., Golhar, D., \& Waller, M. (1996). Development and validation of TQM implementation constructs. Decision Sciences, 1, 23-56. https://doi.org/10.1111/j.1540-5915.1996.tb00842.x

[2] Bartlett, J. E., Kotrlik, J. W. K. J. W., \& Higgins, C. (2001). Organizational research: Determining appropriate sample size in survey research appropriate sample size in survey research. Information Technology, Learning, and Performance Journal, 19(1), 43-50.

[3] Brookshaw, T., and Terziovski, M. (1997). The relationship between strategic purchasing and customer satisfaction within a total quality management environment. Benchmarking for Quality Management and Technology, 4(4), 244-258. https://doi.org/10.1108/14635779710195096

[4] Chin, K., Rao Tummala, V. M., Leung, J. P. F., \& Tang, X. (2004). A study on supply chain management practices: The Hong Kong manufacturing perspective. International Journal of Physical Distribution and Logistics Management, 34(6), 505-524. https://doi.org/10.1108/09600030410558586

[5] Corbett, C. J. (2006). Global Diffusion of ISO 9000 Certification through Supply Chains. Manufacturing and Service Operations Management, 8(4), 330-350. https://doi.org/10.1287/msom.1060.0120

[6] Cousins, P. D., Lawson, B., \& Squire, B. (2006), An empirical taxonomy of purchasing functions. International Journal of Operations and Production Management, 26(7), 775-794. https://doi.org/10.1108/01443570610672239

[7] Das, A. \& Narasimhan, R. (2000). Purchasing Competence and Its Relationship with Manufacturing Performance. The Journal of Supply Chain Management, 36(2), 17-28. https://doi.org/10.1111/j.1745-493X.2000.tb00074.x

[8] Delić, M., Radlovački, V., Kamberović, B., Maksimović, R., \& Pečujlija, M. (2014). Examining relationships between quality management and organisational performance in transitional economies. Total Quality Management and Business Excellence, 25(3-4), 367-382. https://doi.org/10.1080/14783363.2013.799331

[9] Dillman, D. A., Smyth, J. D. \& Christian, L. M. (2008). Internet, Mail, and Mixed-Mode Surveys: The Tailored Design Method. John Wiley and Sons.

[10] Flynn, B. B., Schroeder, Roger, G., \& Sakakibara, S. (1994). A framework for quality management research and an associated measurement instrument. Journal of Operations Management, 11, 339-366. https://doi.org/10.1016/S0272-6963(97)90004-8

[11] Foerstl, K., Hartmann, E., Wynstra, F., \& Moser, R. (2013). Cross-functional integration and functional coordination in purchasing and supply management. International Journal of Operations and Production Management, 33(6), 689-721. https://doi.org/10.1108/IJOPM-09-2011-0349

[12] Giunipero, L. C., Hooker, R. E., \& Denslow, D. (2012). Purchasing and supply management sustainability: Drivers and barriers. Journal of Purchasing and Supply Management, 18(4), 258-269.

https://doi.org/10.1016/j.pursup.2012.06.003 
[13] González-Benito, J., Martínez-Lorente, A. R., \& Dale, B. G. (2003). A study of the purchasing management system with respect to total quality management. Industrial Marketing Management, 32(6), 443-454. https://doi.org/10.1016/S0019-8501(02)00231-6

[14] Hair, J. F. J., Hult, G. T. M., Ringle, C., \& Sarstedt, M. (2014). A Primer on Partial Least Squares Structural Equation Modeling (PLS-SEM). Sage, USA.

[15] Hemsworth, D., Sánchez-Rodríguez, C., \& Bidgood, B. (2008). A structural model of the impact of Quality Management Practices and purchasing-related Information Systems on purchasing performance: A TQM perspective. Total Quality Management and Business Excellence, 19(12), 151-164. https://doi.org/10.1080/14783360701602056

[16] Kaynak, H. (2003). The relationship between total quality management practices and their effects on firm performance. Journal of Operations Management, 21(4), 405-435. https://doi.org/10.1016/S0272-6963(03)00004-4

[17] Kaynak, H. \& Hartley, J. L. (2006). Using replication research for just-in-time purchasing construct development. Journal of Operations Management, 24(6), 868-892. https://doi.org/10.1016/j.jom.2005.11.006

[18] Ketikidis, P. H., Koh, S. C. L., Dimitriadis, N., Gunasekaran, A., \& Kehajova, M. (2008). The use of information systems for logistics and supply chain management in South East Europe: Current status and future direction. Omega, 36(4), 592-599. https://doi.org/10.1016/j.omega.2006.11.010

[19] Koh, S. C. L., Demirbag, M., Bayraktar, E., Tatoglu, E., \& Zaim, S. (2007). The impact of supply chain management practices on performance of SMEs. Industrial Management and Data Systems, 107(1), 103-124. https://doi.org/10.1108/02635570710719089

[20] Martínez-Costa, M., Martínez-Lorente, A. R., \& Choi, T. Y. (2008). Simultaneous consideration of TQM and ISO 9000 on performance and motivation: An empirical study of Spanish companies. International Journal of Production Economics, 113(1), 23-39. https://doi.org/10.1016/j.jpe.2007.02.046

[21] Melnyk, S. A., Lummus, R. R., Vokurka, R. J., Burns, L. J., \& Sandor, J. (2009). Mapping the future of supply chain management: a Delphi study. International Journal of Production Research, 47(16), 4629-4653. https://doi.org/10.1080/00207540802014700

[22] Mentzer, J. T., Stank, T. P., \& Esper, T. L. (2008). Supply chain management and its relationship to logistics, marketing, production, and operations management. Journal of Business Logistics, 29(1), 31-46. https://doi.org/10.1002/j.2158-1592.2008.tb00067.x

[23] Milosevic, D., Djuric, M., Filipovic, J., \& Ristic, S. (2013). Benchmarking as a Quality Management Tool in Public Administration. Engineering Economics, 24(4), 364-372. https://doi.org/10.5755/j01.ee.24.4.2785

[24] Narasimhan, R. \& Schoenherr, T. (2012). The effects of integrated supply management practices and environmental management practices on relative competitive quality advantage. International Journal of Production Research, 50(4), 1185-1201. https://doi.org/10.1080/00207543.2011.555785

[25] Nunnally, J. \& Bernstein, H. (1994). Psychometric theory. New York: McGraw-Hill Inc.

[26] Office of the Republic of Serbia, (2016), retrieved from: http://webrzs.stat.gov.rs/WebSite/.

[27] Paulraj, A., Chen, I. J., \& Flynn, J. (2006). Levels of strategic purchasing: Impact on supply integration and performance. Journal of Purchasing and Supply Management, 12(3), 107122. https://doi.org/10.1016/j.pursup.2006.08.002

[28] Radlovački, V., Beker, I., Majstorović, V., Pečujlija, M., Stanivuković, D., \& Kamberović, B. (2010). Quality
Managers' Estimates of Quality Management Principles Application in Certified Organisations in Transitional Conditions - Is Serbia Close to TQM? Strojniški Vestnik Journal of Mechanical Engineering, 57(11), 851-861. https://doi.org/10.5545/sv-jme.2010.204

[29] Ramsay, J. (2001). Purchasing's strategic irrelevance. European Journal of Purchasing and Supply Management, 7(4), 257-263. https://doi.org/10.1016/S0969-7012(01)00007-7

[30] Ramsay, J. \& Croom, S. (2008). The impact of evolutionary and developmental metaphors on Purchasing and Supply Management: A critique. Journal of Purchasing and Supply Management, 14(3), 192-204. https://doi.org/10.1016/j.pursup.2008.04.001

[31] Sampaio, P., Saraiva, P., \& Guimarães Rodrigues, A. (2009). An analysis of ISO 9000 data in the world and the European Union. Total Quality Management and Business Excellence, 20(12), 1303-1320. https://doi.org/10.1080/14783360903250597

[32] Sánchez-Rodríguez, C. \& Hemsworth, D. (2005). A structural analysis of the impact of quality management practices in purchasing on purchasing and business performance. Total Quality Management and Business Excellence, 16(2), 215-230. https://doi.org/10.1080/14783360500054376

[33] Sánchez-Rodríguez, C. \& Martínez-Lorente, Á. R. (2004). Quality management practices in the purchasing function: An empirical study. International Journal of Operations and Production Management, 24(7), 666-687. https://doi.org/10.1108/01443570410541984

[34] Sánchez-Rodríguez, C., Martínez-Lorente, Á. R., \& Clavel, J. G. (2003). Benchmarking in the purchasing function and its impact on purchasing and business performance. Benchmarking: An International Journal, 10(5), 457-471. https://doi.org/10.1108/14635770310495500

[35] Saraiva, P. M. \& Duarte, B. (2003). ISO 9000: Some statistical results for a worldwide phenomenon. Total Quality Management and Business Excellence, 14(10), 1169-1178. https://doi.org/10.1080/1478336032000107726

[36] Saraph, J. V., Benson, P. G., \& Schroeder, R. G. (1989). An Instrument for Measuring the Critical Factors of Quality Management. Decision Sciences, 20(4), 810-829. https://doi.org/10.1111/j.1540-5915.1989.tb01421.x

[37] Terziovski, M., Power, D., \& Sohal, A. S. (2003). The longitudinal effects of the ISO 9000 certification process on business performance. European Journal of Operational Research, 146(3), 580-595. https://doi.org/10.1016/S0377-2217(02)00252-7

[38] Walder, A. (1996). Markets and inequality in transitional economies: Toward testable theories. American Journal of Sociology, 101(4), 1060-1073. https://doi.org/10.1086/230789

[39] Yamada, T. T., Poltronieri, C. F., Gambi, L. D. N., \& Gerolamo, M. C. (2013). Why Does the Implementation of Quality Management Practices Fail? A Qualitative Study of Barriers in Brazilian Companies. Procedia - Social and Behavioral Sciences, 81, 366-370. https://doi.org/10.1016/j.sbspro.2013.06.444

[40] Yeung, A. C. L., Lee, T. S., \& Chan, L. Y. (2003). Senior management perspectives and ISO 9000 effectiveness: An empirical research. International Journal of Production Research, 41(3), 545-569. https://doi.org/10.1080/0020754021000033896

[41] Schneider, L. \& Wallenburg, C. M. (2013) 50 Years of research on organizing the purchasing function: Do we need any more? Journal of Purchasing and Supply Management, 19(3), 144-164. https://doi.org/10.1016/j.pursup.2013.05.001

[42] Sánchez-Rodríguez, C. \& Martínez-Lorente, Á. (2004). Quality management practices in the purchasing function: An empirical study. International Journal of Operations \& Production Management, 24(7), 666-687. 
https://doi.org/10.1108/01443570410541984

[43] Ram, Narasimhan \& Ajay, Das. (2001). The impact of purchasing integration and practices on manufacturing performance. Journal of Operations Management, 19(5), 593-609. https://doi.org/10.1016/S0272-6963(01)00055-9

[44] Hemsworth, D., Sánchez-Rodríguez, C., \& Bidgood, B. (2005). Determining the impact of quality management practices and purchasing-related information systems on purchasing performance: A structural model. Journal of Enterprise Information Management, 18(2), 169-194. https://doi.org/10.1108/17410390510579909

[45] Runje B., Stepanic J., Mihaljevic M., Horvatic A., \& Kondic V. (2016). Simulation modelling of a company providing two qualitatively different services to market. International Journal of Simulation Modelling, 15(3), 473-484. https://doi.org/10.2507/IJSIMM15(3)7.349

[46] Gocken M., Dosdogru A. T., \& Boru A. (2017). Optimization via simulation for inventory control policies and supplier selection. International Journal of Simulation Modelling, 16(2), 241-252. https://doi.org/10.2507/IJSIMM16(2)5.375

[47] Li Q. Z., Fan X. W., Huang W. J., \& Kwangseek C. (2017) Collaborative supply model and case simulation in a twolevel assemble-to-order system in the context of global purchasing. International Journal of Simulation Modelling, 16(3), 471-483. https://doi.org/10.2507/IJSIMM16(3)9.393

\section{Contact information:}

\section{Bojan LALIĆ, Ph.D.}

University of Novi Sad, Faculty of Technical Sciences

Trg Dositeja Obradovića 6, 21000 Novi Sad, Serbia

E-mail: blalic@uns.ac.rs

Milan DELIĆ, Ph.D.

University of Novi Sad, Faculty of Technical Sciences

Trg Dositeja Obradovića 6, 21000 Novi Sad, Serbia

E-mail: delic@uns.ac.rs

Nenad SIMEUNOVIĆ, Ph.D., Corresponding author University of Novi Sad, Faculty of Technical Sciences Trg Dositeja Obradovića 6, 21000 Novi Sad, Serbia

E-mail: nsimeun@uns.ac.rs

Nemanja TASIĆ, Ph.D

University of Novi Sad, Faculty of Technical Sciences

Trg Dositeja Obradovića 6, 21000 Novi Sad, Serbia

E-mail: nemanja.tasic@uns.ac.rs

\section{Sreten CVETKOVIĆ, M.Sc.}

Regional Center of Ministry of Defence, Novi Sad, Serbia

Futoška 26, 21000, Novi Sad, Serbia

E-mail: sreten1970@gmail.com 